Boise State University

ScholarWorks

Materials Science and Engineering Faculty

Publications and Presentations

Department of Materials Science and Engineering

$10-30-2015$

\title{
The Decision, Implementation and Assessment of a Credit-Bearing Activity Class by Faculty in Residence: A Case Study
}

Janet Callahan

Boise State University

Geoff Harrison

Victoria University

Michael Humphrey

Boise State University

Cala Sielaff

Boise State University

Melissa Wintrow

Boise State University 


\title{
The Decision, Implementation and Assessment of a Credit-Bearing Activity Class by Faculty in Residence: A Case Study
}

\author{
Janet Callahan \\ Materials Science and Engineering \\ Boise State University \\ Boise, Idaho \\ Michael Humphrey \\ Department of Special Education \\ Boise State University \\ Boise, Idaho
}

\author{
Geoff Harrison \\ School of Management \\ Victoria University \\ Wellington, New Zealand \\ Cala Sielaff \\ Fitness Programs \\ Campus Recreation \\ Boise State University \\ Boise, Idaho
}

\author{
Melissa Wintrow \\ Residential Education \\ University Housing \\ Boise State University \\ Boise, Idaho
}

\begin{abstract}
This case study reports on a programmatic decision to require a credit-bearing course that was made by Faculty in Residence (FIR), including its implementation and results over a two-year period from 2010-2012. The focus is on FIR and on the impact of their decision upon the students enrolled in their Living Learning Communities (LLCs). The credit-bearing course was a Kinesiology Activities class taken by all seven LLCs at Boise State University. Anonymous feedback from students was obtained via end of semester surveys; results were used to improve the course. Survey feedback was analyzed to assess the value students perceived to have gained from the course. The majority of students reported gaining value from the class. Students noted that it positively affected their time management/personal accountability, that it decreased their stress level and that it increased their awareness of the Recreational Center offerings. Some students were critical of the course, reporting little to no value or even resentment about the course requirement. The decision, implementation and improvements of the course required faculty leadership and full participation of all LLCs; perceptions of the FIR in terms of the effects of adding the required course on their LLC are reported.
\end{abstract}

Keywords: living learning communities, faculty in residence, residential life, kinesiology, case study, housing

\section{Introduction}

The Residential College program was founded at Boise State University (BSU) in 2004. The academic Deans and Vice Presidents for Student Affairs and Academic Affairs collaborated on funding and implementation of the program, and created a charter document. Residential Colleges exist at BSU under the broader umbrella of Living Learning Communities (LLCs). In 2010-2012 there were five residential colleges with live-in FIR and two interest communities where the FIR (staff or faculty) live outside the residence hall. Approximately 140 students participate annually.

Since the program's inception, approximately 1500 students have enrolled in LLCs through five residential colleges with live-in FIR, and two interest communities which do not have faculty that live in residence but who are led by a staff or faculty member who participates in every other way as FIR. To date, about 20 tenured or tenure-track FIR, ranging from a college dean to newly appointed assistant professors have participated in residential colleges, living in residence. In addition, four professional staff members with instructional and other campus responsibilities have 
participated as out of residence "FIR" in the two interest communities. During the academic year, the FIR met regularly as a team under the direction of the Assistant Director for Residential Education (Asst. Dir.), appointed by Student Affairs and Housing, who supervised the program and coordinated the recruitment and day-to-day management of the program.

The mission of the Living-Learning Communities Program is to enrich student learning through direct connection with faculty who bridge academic and personal life and foster interdisciplinary inquiry. [1] Each of the communities is bound together by common values: Self-Assurance, Community Engagement, Intellectual Curiosity, Love of Learning and Openness and Inclusion. LLCs exist at many institutions of higher education across the country. BSU's Residential College program is distinctive because of the low faculty to student ratio (1:22) and the academic course credit component that connects curricular with co-curricular. These features intensify interactions, raise faculty commitment and engage students. LLCs within large universities and in particular a metropolitan commuter campus are known to have positive impacts on student learning, retention, and faculty development. [2-8]

In the fall of 2010 the Asst. Dir. began exploring additional ways to enhance the connections between the LLCs. Considering the positive outcomes found in freshman interest groups and other learning communities where students take linked courses in a specific cohort [2,3,9-11], the idea to link an additional course that would be in common to all LLC students was introduced to the seven FIR associated with the 2010-2011 LLC program. The Lifetime Recreation community (co-sponsored through Campus Recreation) suggested that we consider a Kinesiology course. After considering the research supporting positive correlations between exercise and physical and mental health, as well as increased academic performance, see below, the FIR unanimously supported the idea for implementation in fall 2011.

The connection between participation in physical activity and mental and physical health has been well researched in both youth and adult populations. Modern sedentary lifestyles have been linked to increased rates of cancer, heart disease, diabetes, obesity and mental health problems [12,13]. Commonly accepted knowledge supported by research has shown that engagement in physical and healthy lifestyle can reduce the onset of preventable medical conditions in both youth and adults. Additionally, research has shown that regular physical activity enhances overall psychological well-being by reducing symptoms of depression, stress and anger [14]. Increases in attention, memory and overall ability to learn have been indicated to be better in aerobically fit individuals with participation in regular physical activity (6 hours a week) having been identified as a factor contributing to increased academic performance $[15,16]$. Research has also indicated that mental health outcomes can be positively impacted when an individual participates in his/her preferred form of activity (aerobic or strength training) [16].

Research and literature on the correlation between physical fitness and cognitive performance has generally focused on youth and the aged population. In both groups a positive association has been identified to exist; however, much of the research in the area does not attempt to directly prove that the more active the person the better their academic performance. On the contrary much of the research generalizes that observed increases in executive function can translate to increased academic performance. Regular physical activity elevates executive functioning by increasing oxygen saturation and the production of neurotransmitters like serotonin and norepinephrine which contribute to enhanced reasoning ability, task focus and attention to detail, problem solving skills and the ability to adapt to new problems and situations - all of which can aid overall academic performance [16,17,18,19]. While the optimal amount of weekly exercise has not yet been identified, it is clear that regular physical activity can enhance an individual's mental, physical and emotional health and in turn contribute toward enhanced academic performance.

\section{Case History}

An existing activity course called Kinesiology Activity 163 (KinAct), Exercise on Your Own Time was selected as the foundation for the course in which LLC students would enroll in fall, 2011 and spring, 2012. This was a onecredit, self-scheduling class requiring two hours of weekly activity. The Asst. Dir. and a FIR worked with the chair of Kinesiology and the instructor to modify the curriculum to offer the broadest range of fitness options and the needed flexibility in students' schedules. Kinesiology agreed to fund the course costs for one year at no additional cost to the students, and the instructor was provided by Campus Recreation. This proved to be an excellent collaboration between Student Affairs and Academic Affairs. The instructor attended several monthly FIR meetings and maintained consistent communication with the Asst. Dir. who coordinated the credit and logistics surrounding the linked course. 
The results of the Case are presented in three sections. First, the perspectives of FIR are given. They were asked to complete the following open-ended questions: (1) What do you recollect on how we decided to implement the creditbearing activity class, and (2) In looking back, what do you think the effect of adding KinAct as a requirement had on your living learning community? Of the four eligible FIR who participated without interruption across the planning year (2010-2011) and first-year of implementation (2011-2012), responses were obtained from three, presented below. Second, the instructor for the credit-bearing activity class was asked for her perspective on the deployment in terms of her observations and lessons learned. Third, the results of an end of semester, anonymous survey are presented that was administered to LLC students at the end of the first semester of implementation in conjunction with the same survey's responses from the implementation one year later.

\subsection{FIR Responses to Questions:}

(1) What do you recollect on how we decided to implement the credit-bearing activity class, and (2) In looking back, what do you think the effect of adding KinAct as a requirement had on your living learning community? These are presented in the voice of the FIR, with little editing beyond text rearrangement.

\subsubsection{FIR 1 -- Community Scholars}

Concerning the Implementation: The original intention for adding the Kin-Act course was two-fold. The first objective was to improve first year students' physical health and lifestyle choices and the second was to increase cross LLC student interactions. By implementing a "roll your own" Kin-Act course, I found that neither of these two objectives was entirely met; however several other benefits became evident in comparison to my four years of experience with LLCs before the implementation of the Kin-Act course.

Concerning the Effect on the LLC: Before the implementation of the Kin-Act course with my LLC, it seemed that the community became "modular." Certain students would only hang out with a small number of community members; or individuals would isolate themselves in their suite before and after community events. There was very little observable "bonding" on a community level. After the implementation of the activity course, there was an observable decline in students forming small groups or cliques within the community and of student isolation. This task was assisted greatly by a heavily participatory Program Assistant (student employee who serves as a mentor and assistant to the faculty), who would reach out to community members and encourage those who struggled with personal connections to participate in the Kin-Act course. Community members' increased participation in Kin-Act correlated with increased participation in "outside the classroom" activities.

There was very little observable evidence from my perspective that the incorporation of Kin-Act improved students' health or lifestyle choices, such as residence hall conduct violations and increased interactions across the LLCs. These two factors are very difficult to measure due to the other programs that were also simultaneously implemented.

As a FIR that has experienced LLCs both with and without KinAct courses, in my opinion, based on reviewing the student evaluations of the KinAct course, I felt that the integration of this course across all LLCs was beneficial to students from the students' perspective. The measurable impact observed between community participation in LLC activities and intra-community collaboration was to such an extent that the program was continued.

\subsubsection{FIR 2 -- Engineering Residential College}

Concerning the Implementation: The decision to move forward with requiring the KinAct course was collectively done using our monthly FIR meetings where we also decided to obtain student feedback about the course. We reviewed that feedback as a group at the end of the first fall semester and also at the end of spring semester. After seeing the spring semester's implementation, we decided that overall, implementing the activity course in fall semester was a resoundingly good thing; but that there was no need to also require it in spring, as students by the end of fall semester were both very well connected in terms of campus facilities and also very aware of the full suite of offerings afforded by the REC center. There were some logistic issues - one of my residents was part of the football team, and another was on track, a third was part of a club team, and a fourth in marching band. These residents were ridiculously busy, yet they cheerfully went along with the requirements and it was only in the second semester that we introduced waivers as a work-around for such students. 
Concerning the LLC: I obtained input from my Resident Assistant, who worked with me in the ERC one year prior to implementation as well as the year we implemented the program. He indicated that he felt that participating in the KinAct requirement forced greater interaction between the residents which led to more shared experiences and a greater sense of community on the floor; that the different suites were less cliquish.

As for me, I was surprised when one student in my living learning community wound up receiving a failing grade in the course. Even when given extra chances, the student did not seem to understand the consequences of receiving a failing grade. Finally, it seemed to me that I encountered my students more inside the REC that year than I did the previous year when KinAct was not a required course. These chance encounters allowed students to see that I valued exercise and my own health by participating regularly in the facilities at the REC.

\subsubsection{FIR 3 -- Lifetime Recreation}

Concerning the Implementation: Initially, the idea of a co-listed course began with the notion that it should be academic in nature; however, as we explored the idea we re-visited the core learning outcomes of the program. We felt that a course should emphasize social opportunities intended to build relationships across the entire learning cohort. Personal patterns of success were then discussed and we identified that data supported that physical activity is an effective tool for stress relief, brain engagement, body health and self-image. Thus we explored the idea of creating a course that obligated students to explore the range of movement-based activity offered by Campus Recreation. In year one, the course was modified on the fly several times to more effectively manage the usage patterns and reporting functions supporting the students enrolled in the course.

Concerning the LLC: Lifetime Recreation was designed to be a community of learners that were drawn together by a common affinity. In year one of the community, 2010-2011, we hosted 22 students who had come from an active background of individual and team sports. We expected that these students would carry the discipline and engagement in sports from high school into their collegiate lifestyle but we were quite surprised that only a small percentage of the students became regular users of the university's wide array of Campus Recreation.

By adding the KinAct course in 2011-2012, we were able to engage the students in the exercise pattern they brought with them to school. The course front-loaded a healthy pattern before they could be drawn to other uses of their leisure time. An increased level of physical activity was an expectation on our part but I did not expect the dramatic increases in social engagement that were a by-product of the course. In the two years that we have offered the course, I have found that the course helped to reduce cliques among students because they were apt to find both workout and social networks, which at times were distinctly separate from each other. This in turn helped to increase engagement in class assignments and discussions. It also helped in moderating behavioral issues when they arose.

\subsection{Activity Course Instructor Feedback:}

During the first semester the course was offered, we learned that students need more consistent access to programs and activities that Campus Recreation provides. Even though the benefits of this class outweigh the complaints that are heard from time to time, there is more need for instructor involvement and education in regard to student exercise and making healthy choices. More individualized attention from the instructor of KinAct would benefit students and possibly increase the long-term adherence to activity, since it is clear that students face an overwhelming number of choices and competing priorities in the first year of college. I relate four student stories below; two from students who proved to be challenging, and two that represent success stories.

\subsubsection{Challenging Situations}

During the first semester a student was encountered that was stubbornly set on proving that a certain method of exercise, cross fit, was more beneficial than anything we had to offer at the recreation center. Unfortunately, cross fit programs are not allowed in the facility as the proper equipment and/or facility for this type of training is not available. This individual felt as though they should be excused from the course due to inadequate access to equipment. Through multiple conversations, a solution was found through explaining opportunities that do exist at the recreation center that could improve his performance in cross fit training. For example, using yoga as a modality to increase joint range of motion, he was able to see the benefit on performance. This was a very challenging student in that he was very strong willed about his perceptions of cross fit. 
Multiple times throughout the first semester, students were encountered who were struggling with body image issues who were intimidated by the facility and/or programs. For students struggling in this way, developing a personal relationship and building trust can help them ease into this environment. However, this was not an easy task due to the fact that it is a self-guided course, which limited their interaction with the course instructor. However, consistent communication was maintained with the Asst. Dir. and the FIR, which allowed for trouble shooting and problem solving opportunities. The FIR created influential relationships with students and were key to student success and connection. They were able to create trust with their students, and then connect them to programs, services and personnel in a supportive way.

\subsubsection{Success Stories}

From the Course Instructor: During the first semester of this course we had multiple students who forged signatures on their activity cards to try to obtain credit for completing an activity that they did not do. One student was particularly problematic. However, through discussions with this student, the hard lesson that comes with academic dishonesty was conveyed which led to a greater understanding of personal responsibility and integrity. This student proved this greater understanding by applying for a position at the student recreation center where he now serves as one of the facility's best staff members; he holds true to his integrity and takes ownership for his actions. His work ethic and overall academic performance improved as a result of working through the situation that he had created.

In the Words of a Student: The concept of this class was highly appreciated. This is actually my second year at a college. Last year at another university, I didn't work out as much my first semester. My classes seemed to take up almost all of my free time and what little free time I had available I devoted to relaxing and having fun. I found myself always needing energy drinks and caffeine to get me through not just my mornings but also my days. I had no energy. It was a terrible cycle until my father recommended finding time a few times a week to work out like I did in high school. My second semester I lost weight, had more energy, felt better about myself and seemed happier. This is why I love Kin-Act so much. What a lot of my peers don't understand is that working out literally makes you happy due to the release of endorphins. This class helped me to organize consistent times to put myself first and go work out. I felt happy, awake, and physically challenged. I enjoyed many of the programs. This semester I have tried Zumba, Hip Hop, Yoga (3 different classes), Core Abs and Cycling. I have also enjoyed the racket ball court and many of the aerobic machines.

\subsection{Survey Results, Fall 2011 and Fall 2012.}

An analysis of 119 survey respondents in fall 2011 and of 96 student respondents in fall 2012 was conducted, see Table 1. As part of the survey, students were asked an open-ended question: "What value did you get from the linked course (KinAct )?" Comments were categorized as described below. Many students had compound comments such as: "I became more fit and was challenged to keep a commitment to my health all semester." This was counted as both a comment about increased fitness level and about it challenging them to keep a commitment to their health. Other compound statements contained comments about difficulties with the logistics of the course that were coupled with "but" statements that acknowledged a positive element; such comments were also counted in the appropriate two categories. The acronyms for each community are: GVC, Global Village Community; COBE, College of Business and Economics Residential College; CSRC, Community Scholars Residential College; ERC, Engineering Residential College, HPRC, Health Professions Residential College; AHRC, Arts and Humanities Residential College; LR, Lifetime Recreation. 
Table 1: Analysis of open-ended question: "What Value did you gain from the linked KinAct course?

\begin{tabular}{|c|c|c|c|c|c|c|c|c|c|c|c|c|c|c|c|c|c|}
\hline \multirow[b]{2}{*}{ Value gained } & \multicolumn{7}{|c|}{ Fall 2011} & \multicolumn{7}{|c|}{ Fall 2012} & \multirow{2}{*}{\begin{tabular}{|l|} 
F2011 \\
Total \\
\end{tabular}} & \multirow{2}{*}{$\begin{array}{r}\text { F2012 } \\
\text { Total }\end{array}$} & \multirow{2}{*}{$\begin{array}{r}\text { F2011/2012 } \\
\text { TOTAL }\end{array}$} \\
\hline & GVC & COBE & CSRC & ERC & HPRC & AHRC & LR & GVC & COBE & CSRC & ERC & HPRC & AHRC & LR & & & \\
\hline $\begin{array}{l}\text { Learning about the REC center's offerings; specific thing (e.g. racquetball, } \\
\text { yoga, zumba) }\end{array}$ & 2 & 4 & 1 & 1 & 1 & 2 & 1 & 0 & 3 & 0 & 6 & 0 & 2 & 3 & 12 & 14 & 26 \\
\hline $\begin{array}{l}\text { Comment about an increased fitness level or statement about current } \\
\text { fitness level }\end{array}$ & 0 & 0 & 1 & 3 & 0 & 1 & 2 & 0 & 0 & 0 & 0 & 0 & 1 & 1 & 7 & 2 & 9 \\
\hline Comment about increased confidence & 0 & 0 & 0 & 0 & 0 & 1 & & & & & & & & & 1 & 0 & 1 \\
\hline $\begin{array}{l}\text { Comment about it affecting time management/held accountable/consistent } \\
\text { schedule }\end{array}$ & 1 & 1 & 2 & 1 & 7 & 2 & 9 & 1 & 6 & 0 & 1 & 2 & 3 & 1 & 23 & 14 & 37 \\
\hline $\begin{array}{l}\text { Comment about having an increased level of activity/getting them out of } \\
\text { their rooms doing something other than hw }\end{array}$ & 1 & 3 & 2 & 0 & 2 & 1 & 0 & 1 & 9 & & 1 & 2 & 5 & 1 & 9 & 19 & 28 \\
\hline Comment about awareness of exercise as a good habit & 1 & 0 & 1 & & & & & & 2 & 1 & 2 & 0 & 2 & 3 & 2 & 10 & 12 \\
\hline Compliment about overall general good value of program & 2 & 2 & 1 & 2 & 5 & 3 & 2 & & & 3 & 1 & 1 & 2 & 2 & 17 & 9 & 26 \\
\hline $\begin{array}{l}\text { Comment about it increasing motivation to exercise \& achieve goals in } \\
\text { general }\end{array}$ & 1 & 0 & 0 & 1 & 2 & 1 & 3 & 0 & 4 & 1 & 2 & 2 & 1 & 4 & 8 & 14 & 22 \\
\hline $\begin{array}{l}\text { Comment about it decreasing stress level; improving outlook on life, } \\
\text { improving ones grades, keeping you relaxed }\end{array}$ & 0 & 6 & 0 & 0 & 5 & 4 & 5 & 1 & 2 & 1 & 0 & 3 & 1 & 0 & 20 & 8 & 28 \\
\hline $\begin{array}{l}\text { Comment about it increasing involvement with community members and/or } \\
\text { making friends }\end{array}$ & 0 & 1 & 1 & 0 & 1 & 2 & 1 & 0 & 2 & 1 & 1 & 3 & 0 & 3 & 6 & 10 & 16 \\
\hline $\begin{array}{l}\text { Comment about it challenging them to keep a commitment to their health; } \\
\text { health in general }\end{array}$ & 0 & 1 & 0 & 0 & $\frac{1}{24}$ & $\frac{1}{18}$ & $\frac{1}{24}$ & 0 & 2 & $\frac{1}{8}$ & $\frac{1}{15}$ & 3 & $\frac{0}{17}$ & 3 & 4 & $\frac{10}{110}$ & 14 \\
\hline TOTAL comments about value gained & 8 & 18 & 9 & 8 & 24 & 18 & 24 & 3 & 30 & 8 & 15 & 16 & 17 & 21 & 109 & 110 & 219 \\
\hline \begin{tabular}{|l|l} 
Neutral comment \\
\end{tabular} & & & & & & & & & & & & & & & & & \\
\hline Comment about already being active/having good healthy habits & 1 & 0 & 3 & 6 & 0 & 0 & 0 & 1 & 2 & 0 & 2 & 3 & 0 & 1 & 10 & 9 & 19 \\
\hline Criticism: & & & & & & & & & & & & & & & & & \\
\hline Comment about it increasing stress level & 3 & 3 & 1 & 3 & 0 & 2 & 1 & & & & & & 3 & & 13 & 3 & 16 \\
\hline Comment about a failing grade & & & 1 & & & & & & & & & & 1 & & 1 & 1 & 2 \\
\hline $\begin{array}{l}\text { Comment about "no value" e.g. None, Nothing, None whatsoever; overall } \\
\text { resentment "I don't like someone telling when and how to be healthy and it } \\
\text { really bothers me when someone tells me how long to work out for" }\end{array}$ & 2 & 4 & 3 & 1 & 1 & 3 & 4 & 1 & 2 & & 4 & 2 & 1 & 1 & 18 & 11 & 29 \\
\hline Comment about logistics of course (difficulty finding someone to sign, etc.) & 1 & & 2 & 4 & & 1 & & & 1 & & 2 & 1 & 2 & & 8 & 6 & 14 \\
\hline TOTAL critical remarks & 6 & 7 & 7 & 8 & 1 & 6 & 5 & 1 & 3 & 0 & 6 & 3 & 7 & 1 & 40 & 21 & 61 \\
\hline
\end{tabular}

Some observations about the student comments are presented below:

- For all but one community (HPRC), there were fewer criticisms relative to values gained in 2012 as compared with 2011. This is attributed to the improved logistics and lessons learned in the fall 2011 first-semester deployment.

- Comments with positive value gained $(\mathrm{N}=219)$ were greater in number than critical comments $(\mathrm{N}=61)$. However, the number of critical comments is non-trivial, particularly given that there were 29 discrete comments about the course being of "no value" to them.

- 19 students explicitly commented that they already were active/had good healthy habits; 8 of these 19 comments were made by students in the ERC.

- Interestingly, 37 students noted that it affected their time management/held them accountable. Also, 22 students commented about it increasing their motivation to exercise and helping them achieve their personal goals in general. These two sets of comments are the ones that most closely connect with improved academic performance, although not explicitly named that by the students.

- Other categories receiving many positive comments were: that students learned about the Rec center's offerings ( $\mathrm{N}=26)$; that it increased their level of activity/got them out of their room $(\mathrm{N}=28)$; that it decreased their stress level $(\mathrm{N}=28)$ and that it was overall a generally good program $(\mathrm{N}=26)$.

- No students mentioned any increased or more meaningful connections with faculty as a result of the KinAct course - this was expected, since the course was not taught by the FIR.

- Negative comments were concentrated into three categories: comments about the course increasing their stress level ( $\mathrm{N}=16)$; comments about it having "no value" $(\mathrm{N}=29)$ and comments about difficulties associated with the logistics of the course $(\mathrm{N}=14)$.

- Students in Lifetime Recreation seemed more aware of their motivation to exercise; 7 out of the 22 comments about motivation were from individuals in LR over 2 years. 10 out of 37 comments about the program affecting their time management were also made by LR students. Another 9 of the comments about time management were made by students in HPRC.

- 12 out of 28 comments about having an increased level of activity were made by COBE students. 


\section{Discussion}

After the first year of implementing the activity course, the activity course was critically evaluated in terms of its value added to the LLCs. In the first two semesters of the course being offered as part of the LLC experience, the pass rate on the activity course was 87.6 and $86.2 \%$, for an enrollment of 177 and 116 students, respectively. This was of concern to the FIR, as reflected for example in the comment by FIR \#2. Critical evaluation of student comments led to several changes in the program in order to better meet the needs of the students. Changes included improving the program delivery, including a change in the frequency of the KinAct course requirement from fall and spring semesters to fall semester only; and also a plan to better communicate the goals/objectives of an LLC program that included a KinAct course, described in more detail below. Although these changes did not affect the overall pass rate the following semester (83\%), they probably resulted in an increase in "value added" comments rendered by students.

\subsection{Meeting the Needs of the Students}

Because a LLC is a dynamic system, in order for it to be effective, the management team, including the FIR, must be dynamic in the LLC pedagogical and programmatic delivery. This case study exemplifies how dynamic and collaborative this implementation was, as many changes occurred between the first and second year of the activity class.

One of the first issues the leadership team undertook to mitigate was identifying possible exceptions to what was in the first year, an all-inclusive rule that required all participants to enroll in the KinAct class as part of their course load. Many of the LLCs had members who were actively participating in a high level of physical activities. These activities included varsity sports, club/intramural sports and ROTC. In the second year of implementation, a waiver was introduced wherein a FIR could identify and waive a member within their LLC from the activity course requirement. Several FIR also identified members who had a health impairment that would make participation in the course inadvisable to their health. Approximately ten waivers were issued in fall 2012 out of a total community that comprised 140. Allowing waivers met the needs of the students without adding barriers to student success while also meeting the LLC goals of increased community.

\section{$\underline{3.2 \text { Improving Program Delivery }}$}

After analyzing the feedback from the LLC members during the first year of the activity course implementation, the leadership team radically changed how the activity course component was introduced to students. As a tradition that has occurred since the inception of the LLC program on this campus, all residential colleges gather the Saturday before classes for an introduction to the Living Learning Communities and their individual residential colleges. This occurs approximately within the first 24 hours of a student moving into the residential halls and generally lasts 2 to 3 hours, including brunch. This is a very important meeting; it introduces the LLC as a community of communities, and for the vast majority of LLC members, it is their "first day of college." During the fall 2011 semester, the Activity Course Instructor led a presentation about the activity course during this timeframe to all of the LLC students, staff and faculty gathered in the meeting hall (an audience of approximately 160). Based on student feedback obtained from fall 2011, this was subsequently identified by the LLC leadership team to be an ineffective way to present critical information associated with a course they would begin the following week. In order to alleviate the confusion associated with the fall's activity course offering, a second presentation about the activity course was given at the beginning of the spring 2012 semester. This second presentation was held at the student recreation center, and was interactive, with students going from station to station within the REC center, learning about the different offerings. It opened up opportunities for LLC members to visit the "classroom" area as one of the stations, where they received the course syllabus and the course requirements were explained. It ended with several fun activities, including volleyball matches, basketball games and more. The FIR and the students participating in the event identified this interactive presentation to be a great success. Over summer 2012, the introduction of the activity component was reworked one more time to an improved hybrid, wherein the Activity Course Instructor introduced the course to the LLC both on the Saturday before courses started and also with the interactive presentation at the student recreation facility during the first week of courses with all FIR in attendance. This improvement of this method of introducing the physical activity component of the LLC was perceived in LLC student evaluations obtained in fall of 2012. 


\subsection{Using the Activity Course as a Method of Creating Community}

All three FIR reported a perceived decrease in the formation of exclusive social groups, or "cliques" as a possible result of the activity course. The formation of exclusive social groups had been previously identified as an issue in several of the communities, and was something that the Asst. Dir. actively worked with program assistants to help avert. The implementation of the KinAct course involved a pedagogy designed to increase cross-community connections, so it was not surprising that it helped alleviate this issue. Albeit these are informal observations only, future work will need to investigate the effects of a course in common across all LLCs that involves informal interactions of students as it might affect the formation of broader social networks than are normally formed in firstyear residential halls.

\section{$\underline{\text { 3.4 Sustainability }}$}

In order to be able to fund the increased the administrative costs and the Activity Course Instructor's salary a nominal $\$ 10.00$ fee was added to the cost of participating in the LLC program. This additional $\$ 1,500-\$ 1,800$ in revenue was purposefully kept low in order to keep the financial cost of being a LLC member in check.

\section{Summary}

This Case represents the history and deployment of a creative programmatic decision made by FIR to augment the LLC experience at this campus by requiring a credit-bearing kinesiology course. This enabled cross-community interactions and connected students with campus resources and with each other in environments outside their own LLC. Students reported on value gained from the experience including a positive effect on their time management/personal accountability, a decreased stress level and an increased awareness of Rec Center offerings. Some students were critical and/or resentful of the course requirement. FIR reported greater community engagement and fewer interactions as cliques. This Case exemplifies the kind of innovative practice that can result from the rich environment created when academics intersects with residential life and other vital student-centric campus entities such as recreational services. The influence of this Case has guided the selection of FIR for future communities in the following ways: high levels of collaboration, thinking of the "whole" student (not just their grades), sharing idea development and implementation across university departments.

\section{Acknowledgments}

The authors would like to acknowledge the support for the Living Learning Community Program at Boise State University and in particular acknowledge the support of the Provost, the Vice Provost, the Dean of Students, the Director of Housing and Residence Life, Campus Recreation, and the Department of Kinesiology.

\section{References}

[1] http://housing.boisestate.edu/livinglearningcommunities/

[2] Astin, AW. What matters in college: Four critical years revisited. San Francisco: Jossey-Bass; 1993.

[3] Chickering, AW., and Gamson, ZF. Seven Principles for Good Practice in Higher Education. AAHE Bulletin, 39; 1987.

[4] Endo, J., and Harpel, R. The effect of student-faculty interaction on students' educational outcomes. Research in Higher Education. Volume 16, Issue 2, pp 115-138; 1982.

[5] Inkelas, K., Brower, AM. Living Learning Programs: One High-Impact Educational Practice We Now Know a Lot About. Liberal Education, Vol. 96, No. 2; 2010.

[6] Lenning, OT, and Ebbers, LH. The Powerful Potential of Learning Communities: Improving Education for the Future. ASHE-ERIC Higher Education Report, Vol. 26, No. 6. Washington D.C.: The George Washington University, Graduate School of Education and Human Development; 1999.

[7] Shapiro, N. Creating Learning Communities: A Practical Guide to Winning Support, Organizing for Change, and Implementing Programs. San Francisco: Jossey-Bass; 1999.

[8] Miller, S., Pyke, P., Moll, A., Wintrow, M., Schrader, C., Callahan, J. Successes of an Engineering Residential College Program Within an Emerging Residential Culture. American Society for Engineering Education Annual Conference \& Expo, Austin, TX AC 2009-1113; 2009. 
This is an author-produced, peer-reviewed version of this article. The final, definitive version of this document can be found online at Work, published by IOS Press. Copyright restrictions may apply. doi: 10.3233/WOR-152183

[9] Kuh, G. D., Shouping, H. The Effects of Student-Faculty Interaction In the 1990s, The Review of Higher Education, Vol. 24, No. 3; pp. 309-332; 2001.

[10] Tinto, V., and Goodsell, A. A Longitudinal Study of Freshman Interest Groups at the University of Washington. University Park, Pa.: National Center for Postsecondary Teaching, Learning and Assessment; 1993.

[11] Tinto, V., and Goodsell, A. Freshman Interest Groups and the First-Year Experience: Constructing Student Communities in a Large University. Journal of The First-Year Experience \& Students in Transition, Vol. 6, No. 1; 1994.

[12] Stroth S., Hille K., Spitzer M., Reinhardt R. Aerobic endurance exercise benefits memory and affect in young adults. Neuropsychological Rehabilitation: An International Journal. 19:2, 223-243; 2009.

[13] Hillman, CH., Erikson, KI., Kramer, AF. Be Smart, exercise your heart: Exercise Effects on Brain and Cognition. Nature Reviews Neuroscience: Science and Society. 58-65; 2008.

[14] Hassmen, P., Koivula, N., \& Uutela, A. Physical exercise and psychological well-being:

A population study in Finland. Preventive Medicine. 30:1, 17-25; 2000.

[15] Irandoust, M, Karlsson, N. Impact of Preferences, Curriculum, and Learning Strategies on Academic Success. Education Economics. 10:1, 41-48; 2002.

[16] Colocombe SJ., Kramer AF. Fitness effects on the cognitive function of older adults: A meta-analytic study. Psychological Science. 14:2, 125-130; 2003.

[17] O’Connor P., Herring M., Caravalho A. Mental Health benefits of Strength Training in Adults. American Journal of Lifestyle Medicine; The Med Review. 4:377-396; 2010.

[18] Medina, J. Brain Rules: 12 Principles for surviving and thriving at work, home and school. Pear Press. Seattle, WA; 2008.

[19] Ploughman, M. Exercise is Brain Food: The Effects of Physical Activity on Cognitive Function. Developmental Neurorehabilitation. 11(3):236-240; 2002. 